\title{
Community-Based Flood Risk Management in a Dense Populated Floodplain Area
}

\author{
Laksni Sedyowati $^{1}$, Grahita Chandrarin ${ }^{1}$, Ginanjar Indra kusuma Nugraha ${ }^{1}$ \\ \{laksni.sedyowati@unmer.ac.id, grahitac@unmer.ac.id,gim_revalin@unmer.ac.id\} \\ ${ }^{1}$ University of Merdeka Malang, Jl. Terusan Raya Dieng No. 62 - 64, Malang, Indonesia
}

\begin{abstract}
Flood risk management in a floodplain area with high population density has complex challenges. Almost all communities in that area are unwilling to move even though they are aware of the potential for flooding. This study aims to: 1) develop knowledge and understanding of community-based flood risk management in Malang City, Indonesia; 2) assess the cost effectiveness of the flood risk management; 3) develop a framework for building community-based flood risk management. This study used a mixed method combining quantitative and qualitative approaches. The results show that the understanding of the flood risk and the potency of flood emergency response of the local government significantly influence building communitybased flood risk management system. This system can reduce the flood risk up to $30 \%$ compared to before the implementation of that system, and provides direct financial benefits. The total benefit can be cost effectiveness of up to $49.2 \%$ in a year.
\end{abstract}

Keywords: Cost effectiveness analysis; flood risk management; flood resilience; local wisdom; community participation.

\section{Introduction}

Precipitation resulting from climate change often causes floods and inundation. A risk assessment in urban areas is necessary for the event of extreme precipitation [1]. Flood and inundation occur mainly in the built-up area, especially at the crossroads [2]. The reduced open area as a result of uncontrolled urban development has the potential to produce high runoff discharge, especially during heavy rains. Many studies examine the problem of urban flooding and its resolution, including the use of permeable pavement [3]-[6]. However, flood control infrastructure has not significantly reduced the risk of global flooding, as shown by the average annual flood events and losses, 2000-2015 [7]. A significant obstacle to flood control efforts is the lack of proactive responses to anticipate disasters. Currently, the actions taken are reactive responses after a disaster occurs, such as emergency response and 
recovery [8]; efforts are more structural than non-structural measures [9]; lack of roles and authority given to the community [10] and multi-stakeholder [11]; and for each different region there is no specific adaptation approach related to the development of urban flood resilience systems [12]. Non-structural measures have the advantage of being environmentally friendly and economically efficient, but their effectiveness is sensitive to the socioeconomic context and government behavior [13].

The paradigm of controlling floods from conventional methods to modern methods has already changed. There have been significant changes in efforts to reduce flood risk, from hard technical foundations to softer basics such as integrated flood management, flood risk management (FRM), risk sharing in flood management [14], and flood resilience systems [9]. To increase the effectiveness of disaster risk management and reduce the loss of lives and property, efforts should be directed towards proactive responses. Proactive disaster management requires more participation from stakeholders, such as government, non-government and private institutions, and community participation. This has implications for more effort and time, a higher budget, and more equipment, facilities, and human resources, which leads to the integration of long-term and short-term programs for flood disaster management [8]. Urban systems that implement a protection system by engaging communities independently can avoid greater damage. Building on some previous experiences, the shape of the system can be adjusted to adapt to the problems and disruptions that occur in the region. Differences in urban systems (institutions, levels of urbanization, assets, the culture of existing risk, and financial preparedness) affect the level of disruption created during and after floods and reflect the resistance to flooding in urban systems [15]. The constraints that arise in community flood risk management, such as lack of financial resources, cause the "aid dependency" syndrome which can be an obstacle to the success of the program. Lack of funding sources and local ownership are also major challenges for the sustainability of the program. Identifying challenges explains limitations and guides how improvements are needed, thus making a valuable contribution to the existing knowledge base [16].

To seek the best alternative method of flood risk management, cost effectiveness analysis (CEA) can be used to combine the net costs of the measure provided and the results with their effectiveness, the costeffectiveness ratios of which can then be used to compare the measures with alternative measures that aim to achieve the same goals, such as behavior change, good yield improvement, or a decrease in negative outcomes [17]. The final decision should be defined before the implementation of the program 
[18]. In flood risk management it is found that by incorporating broader value benefits, economic viability will increase significantly so that in the end recommendations regarding incentives and policies to increase efforts to reduce flood risk are provided [19].

Malang City, the second-largest city in East Java Province, is experiencing rapid urban development and changes in the characteristics of the rain due to climate change. It causes floods and inundation during the rainy season. The local government has implemented many flood prevention efforts, but so far no optimal results have been observed. This study aims to assess the costeffectiveness of flood risk management considering all the benefits, both monetary and non-monetary, and to develop a framework of community-based flood risk management in a densely populated floodplain area.

\section{Materials and Methods}

\subsection{Description of Study Area}

Malang City with a hilly topography with five rivers flowing through that have excellent flow characters [20] should not have significant flood problems. However, Kampong that located in a densely populated area on the edge of the drainage channel has a significant flood problem. This kampong is known as Glintung Water Street (GWS) because with each heavy rain, the roads within a radius of about $100 \mathrm{~m}$ from the river become a floodway. With a population of 810 inhabitants and an area of 8.2 ha, the region has a population density of approximately 9,900 inhabitants $/ \mathrm{km}^{2}$. Since the beginning of 2000, almost $50 \%$ of the area has been flooded each rainy season with an average flood height of 0.7 meters and a maximum of 1.5 meters. There is a large 10-meter wide canal at the southern limit, a highway to the west, a crowded neighboring kampong to the north, and a railroad to the east. The three border areas have a higher elevation than Glintung Kampong, so this area becomes like a pool of water during the rainy season. This condition worsens because there is water flow when the water level in the canal rises and the canal water then overflows into the kampong. Figure 1 shows the level of water after a stormwater runoff in the study area. 


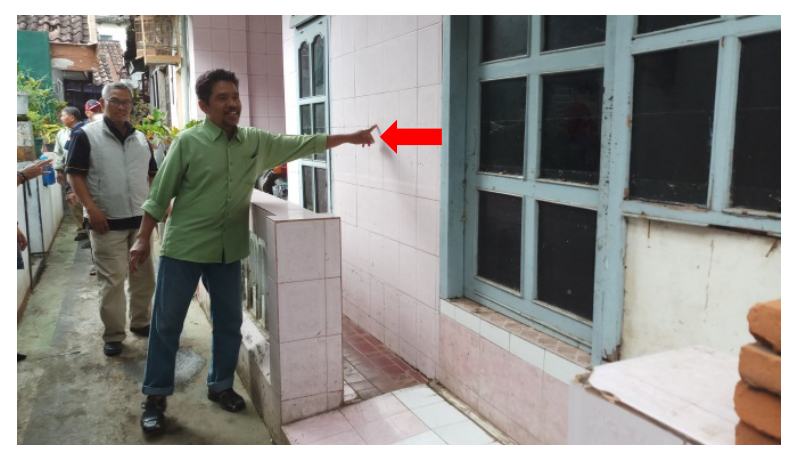

Fig.1. Flood level mark at the study area

\subsection{Cost Effectiveness}

Cost effectiveness analysis (CEA) is a decision-making tool that considers several alternative actions taken. There has been an increase in the use of CEA in recent years. The core concept of CEA is quite simple: to combine the net costs of the intervention provided and the results with their effectiveness, then to use the cost-effectiveness ratios produced to compare the interventions with alternative interventions that aim to achieve the same goals (behavior change, good yield improvement, or decrease in negative outcomes). The cost effectiveness ratio can be calculated differently depending on whether the intervention provided must be chosen rather than the alternative, or whether it can be combined with several alternatives [17]. There are four initial considerations and five important steps in conducting CEA [18]. Initial considerations consist of determining the baseline, selecting the appropriate results, determining the prospective costs, and time horizons. The baseline can be an existing program or societal conditions. The first step in conducting CEA is to develop research questions that are clearly defined. The second step is to design a decision analysis mechanism to graphically describe the order in which the intervention occurs. The third step is quantifying the costs and results. The fourth step is determining the cost-effectiveness ratio (CER) and incremental cost-effectiveness ratio (ICER), and the final step is examining uncertainty by conducting a sensitivity analysis to test the robustness of the conclusions of the economic evaluation. Good justification of a program or intervention in terms of cost and effectiveness should be ensured before being implemented. Therefore, the decision-making process for the efficient allocation of resources can be facilitated through economic evaluation studies using CEA. 


\subsection{Research Method}

This study is a mixed-method that combined a quantitative method using questionnaire distribution (43 respondents from 162 families) with a qualitative method using in-depth interviews (10 informants) and field observations. Quantitative methods are used to determine the factors that influence flood resilience systems and flood risk management that already exist in the community. Factors identified include community concern for the environment, community behavior in the face of flooding, community participation in flood risk management, including their response to government flood risk reduction programs. The questionnaire was also used to examine the risk of flooding and the level of community resilience to frequent flooding. In-depth interviews were conducted to find out the reasons why the community stayed in the floodplains, the loss of floods that have occurred over the past 10 years, and the community values used in the flood resilience system that naturally formed in the community. Field observations were made to understand the existing community flood resilience system, the interaction of local communities with local governments and associated institutions, as well as the community's creativity, innovation, and potential of the local community in developing cost effectiveness.

Questionnaires. The questionnaire consisted of seven question categories as follows: 1) Community awareness of and participation toward protecting the environment; 2) Understanding of the causes of floods; 3) Understanding of the risk of flooding that occurs around the residence; 4) Flood emergency response; 5) Understanding of risk management and flood resilience systems; 6) flood warning system; 7) Responses to flooding control efforts from the Government. Respondents consisted of two groups, namely groups of community leaders and community groups. The community groups consisted of the male group and female groups. The answers from respondents to the questions on the questionnaire were directed at four alternative answers according to the Likert's Scale. The four alternative answers are: constantly, score 4; frequently, a score of 3; rarely, score 2; never, score 4 . The data was then analyzed using reliability and validity tests. The completion of the questionnaire was carried out through direct interviews with respondents and the answers were directly filled in the appropriate column. Questionnaire data were then analyzed using correlation, determination, and regression analysis tests.

In-depth Interview. In-depth interviews were conducted with 10 community leaders as informants, namely: RW Chairman (one person), PKK RW 
Chairman (one person), RT Chairpersons (five people), Takmir Masjid Chairman (one person), Karang Taruna Chairman (one person), elders (one person) and related local government agencies. Interviews were also conducted to explore the role of relevant agencies in developing community potential towards food security, environmental sustainability, and the facilities provided.

Field Observation. To obtain the data needed, observations were undertaken according to a schedule agreed upon by the community and the interviewer with the following provisions in place: 1) During heavy rains with the inundation depth reaching $1 \mathrm{~m}$, observations were conducted at drainage channels and where streets functioned as floodways; 2) When there is no rain, observations were conducted at the drainage canal that also functions as a fish pond; 3) Observations also conducted at the community meeting activities with related agencies, community health center, local women organization's meetings, religious activities, youth activities, and community services. The data were then analyzed using Correlation Rest and Regression Analysis to find the validity and the reliability of the data, and the relationship of the parameters observed. Evaluation of changes in flood risk due to additional treatment, both structural and non-structural programs, is carried out with measurements before and after the program.

Results from in-depth interviews and field observation (qualitative results) were also used to verify the quantitative result from questionnaire data, so as the results of the quantitative analysis can be generalized

\section{Results and Discussions}

\subsection{Design Parameter Analysis}

In this study, the design parameter is the existence of a system of flood resilience and risk management. The influencing factors were identified based on the results of in-depth interviews and field observations. There are six parameters identified which are then used as research variables. Therefore, there are seven variables used, i.e. one dependent variable and six independent variables. The variables are as follows: 1) flood resilience and risk management system (Y);2) understanding the causes of floods (X1); 3) understanding the flood risk (X2); 4) flood emergency response of the community leaders (X3); 5) community awareness and participation (X4); 6) existence of flood warning system (X5); 7) responses to government programs 
(X6). The correlations between variables were analyzed using a correlation test and regression analysis. Data analysis was based on three categories or groups of the respondents: 1) community leaders $(N=10)$; 2$)$ male respondents $(N=26)$; female respondents $(N=17)$.

Reliability and Validity Tests. The most influencing factors in building flood resilience and risk management system were obtained based on the results of a questionnaire analysis of 43 respondents. The questionnaire was analyzed to get measurable data from seven variables consisting of one dependent variable and six independent variables, as described above. Based on the reliability questionnaire test simultaneously all variables obtained Cronbach's Alpha value of 0.72 (greater than 0.6 ) which means that the questionnaire instrument used is reliable [21] and the dependent variable can be further analyzed using regression analysis. The validity of the question category in the questionnaire was analyzed simultaneously and the resulting validity coefficient at the value of 0.75 . The results of the calculation of P-value at the significance level of 0.00 , lower than 0.05 [22] as shown in Table 2.

Table 1. Results of reliability test for each category of question

\begin{tabular}{llcll}
\hline Code & Variables & $\begin{array}{l}\text { Cronbach } \\
\text { Alpha }\end{array}$ & $\begin{array}{l}\text { Standard } \\
\text { Value }\end{array}$ & Significance \\
\hline X1 & Understanding the causes of floods & 0.66 & 0.6 & reliable \\
X2 & Understanding the flood risk & 0.72 & 0.6 & reliable \\
X3 & Flood emergency response of the & 0.79 & 0.6 & \\
& community leaders & & & \\
X4 & Community awareness and participation & 0.64 & 0.6 & reliable \\
X5 & Existence of a flood warning system & 0.62 & 0.6 & reliable \\
X6 & Responses to government programs & 0.01 & 0.6 & Not reliable \\
\hline
\end{tabular}

Table 2. Results of validity test for each category of question

\begin{tabular}{lllll}
\hline Code & Variables & r & P-value & Significance \\
\hline X1 & Understanding the causes of floods & 0.31 & 0.16 & Not valid \\
X2 & Understanding the flood risk & 0.76 & 0.00 & valid \\
X3 & $\begin{array}{l}\text { Flood emergency response of the } \\
\text { community leaders }\end{array}$ & 0.80 & 0.00 & valid \\
X4 & Community awareness and participation & 0.37 & 0.07 & \\
X5 & Existence of a flood warning system & 0.46 & 0.11 & Not valid \\
X6 & Responses to government programs & 0.15 & 0.74 & Not valid \\
\hline
\end{tabular}

Correlation and Determination Coefficients. The strength of the relationship between variables in this study is shown by the correlation coefficient, while the influence of each independent variable on the dependent 
variable is shown by the determination coefficients. Correlation coefficients and determination coefficients are complete as shown in Table 3 and Table 4 below.

Tabel 3. Correlation coefficients between variables

\begin{tabular}{llllllll}
\hline $\begin{array}{l}\text { Variables } \\
\text { Code }\end{array}$ & \multicolumn{1}{c}{ Y } & X1 & X2 & X3 & X4 & X5 & X6 \\
\hline Y & 1.00 & & & & & & \\
X1 & 0.22 & 1.00 & & & & & \\
X2 & 0.66 & 0.15 & 1.00 & & & & \\
X3 & 0.70 & 0.32 & 0.68 & 1.00 & & & \\
X4 & 0.28 & 0.16 & 0.33 & 0.48 & 1.00 & & \\
X5 & 0.38 & 0.23 & 0.40 & 0.66 & 0.29 & 1.00 & \\
X6 & -0.05 & 0.05 & -0.19 & -0.05 & 0.16 & 0.13 & 1.00 \\
\hline
\end{tabular}

Tabel 4. Determination Coefficients $\left(\mathrm{r}^{2}\right)$ resulted from regression analysis

\begin{tabular}{lllll}
\hline Code & Variables & $\mathbf{r}^{\mathbf{2}}$ & P-value & Significance \\
\hline X1 & Understanding the causes of floods & 0.05 & 0.16 & no \\
X2 & Understanding the flood risk & 0.43 & 0.00 & yes \\
X3 & Flood emergency response of the & 0.49 & 0.00 & yes \\
& community leaders & & & \\
X4 & Community awareness and participation & 0.08 & 0.07 & no \\
X5 & Existence of a flood warning system & 0.15 & 0.11 & no \\
X6 & Responses to government programs & 0.00 & 0.74 & no \\
\hline
\end{tabular}

The results, as described in Table 1, Table 2, Table 3, and Table 4 show that the risk management and flood resilience systems that have developed naturally in the community are strongly influenced by a good understanding of flood risk and flood emergency response by local community leaders. Whilst the response to government programs does not contribute to the implementation and sustainability of the program, it even had a negative correlation. Indeed, the community flood resilience system was in place before the government implemented flood control programs in the study area. This is contrary to the results of research by Šakić Trogrlić et al [16] which asserts that lack of financial resources causes people to be "aid dependency" from both government and other parties, which can be an obstacle to the success of the program. The financial limitations encourage people to develop creative and innovative ideas such as using drainage channels for fish farming and growing vegetables. A sense of community ownership keeps the effort growing, the financial benefits increasing so that the sustainability of the program is maintained. On the other hand, community awareness and participation do not have a significant influence on the program. This is 
because the community is always responsive to the dangers of flooding. Only a small part of the community within $100 \mathrm{~m}$ of the river has been proactive. These results support Tingsanchali's research [8] who states that efforts should be directed towards proactive responses. According to the community, the existence of the flood warning system also does not have a significant effect on the implementation of the program because the community already has a flood warning system with simple technology that is already working well. The community also does not feel the need to understand the cause of the flooding as they realized that they are living in a floodplain area.

Multiple Regression Analysis. The results of the reliability and validity tests show that only two valid variables i.e. understanding of flood risk (X2) and local government flood emergency response (X3) as indicated by Cronbach's Alpha are greater than 0.6 and the P-value is greater than 0.05. Multiple regression analysis was then performed using these two variables and produced the following equation.

$Y=0.66+0.19 X_{2}+0.32 X_{3}$

The equation was then tested using Nash-Sutcliffe efficiency (NSE), root means square error (RMSE) and mean absolute error (MAE). The complete results are presented in Table 5.

Table 5. Results of efficiency and error test

\begin{tabular}{lll}
\hline No & Type of Test & Test Values \\
\hline 1 & Nash-Sutcliffe efficiency & 0.71 \\
2 & Root Mean Square Error & 0.30 \\
3 & Mean Absolute Error & 0.23 \\
\hline
\end{tabular}

The results of the efficiency and error test the design parameters equation as presented in Table 5 show that the model has a good efficiency in estimating the potential existence of risk management and floods resilience systems based on the understanding of flood risk and the flood emergency response of the local government owned by a community.

\subsection{Cost Effectiveness Analysis}

The cost effectiveness analysis was initialized by identifying the whole cost and benefit of the flood resilience system and risk management that have already been implemented, both monetary and non-monetary values. The 
calculation of cost effectiveness was categorized into three conditions, as follows:

1) Condition 1: Before the implementation of the drainage channel and resilience system.

2) Condition 2: After the implementation of the drainage channel utilized for fish and vegetable farming.

3) Condition 3: After drainage channel is utilized for fish and vegetable farming, and with a flood resilience system.

Table 6. Cost effectiveness calculation in 2018-2019, in million Rupiahs

\begin{tabular}{llrrr}
\hline No. & Components & Condition 1 & Condition 2 & Condition 3 \\
\hline 1 & 94.07 & 75.25 & 41.39 \\
& $\begin{array}{l}\text { Flood losses (in } \\
\text { million Rp.) }\end{array}$ & 0 & 178.54 & 178.54 \\
\hline 2 & $\begin{array}{l}\text { Investment cost of the } \\
\text { drainage channel }\end{array}$ & 0 & 2.55 & 2.55 \\
\hline 3 & $\begin{array}{l}\text { Operation and } \\
\text { maintenance }\end{array}$ & 0 & 36.50 & 36.50 \\
\hline 4 & $\begin{array}{l}\text { Revenue from fish } \\
\text { and vegetable farming }\end{array}$ & 0 & 43.31 & 77.18 \\
\hline 5 & Benefit & 0 & 30.50 & 49.20 \\
\hline 6 & $\begin{array}{l}\text { Cost effectiveness } \\
(\%)\end{array}$ & & & \\
\hline
\end{tabular}

Table 6 represents the calculation of the cost effectiveness of the three conditions. It can be seen that in Condition 2, the investment cost of constructing the drainage channel (almost 180 million rupiahs or 12,752.5 USD) can provide benefits, that is the reduced flood losses, and income from fish and vegetable yields which reached 652 USD per month, so there is the cost effectiveness of $30.5 \%$ in a year. Whereas in Condition 3 , the reduction in flood losses was greater as a result of the implementation of the flood resilience system. It affected the cost effectiveness increased to $49.2 \%$ in a year. Therefore, government investment in the future on flood control programs to this kampong will provide more benefits and added value of about $49.2 \%$. This result is in accordance with a study by Sedyowati [23] stated that flood control project provides economic efficiency resulted from the flood risk management system until 90 percent along the 6-year effective lifetime of the project.

\subsection{Community-Based Flood Resilience System Framework}


Based on the discussion above, a framework to build a community flood resilience system for other floodplain was developed. The framework consists of six steps that forming a cyclic diagram as shown in Figure 10 below. Steps in the framework continue to cycle without interruption, but the target achievement will increase according to the evaluation results in the form of a continuous improvement program. There will be an increase at each end of the round so that the diagram will be forming a spiral. The round will end in the best outcome goals set jointly by the community and all stakeholders. This cyclic framework inline with the IWRM Planning Cycle [24]. This cycle continues to spin up. Each round goes through an evaluation phase. If the target results are not yet achieved, the program will be improved, but if the target has been achieved, at the next round the target will be increased (known as continuous improvement).

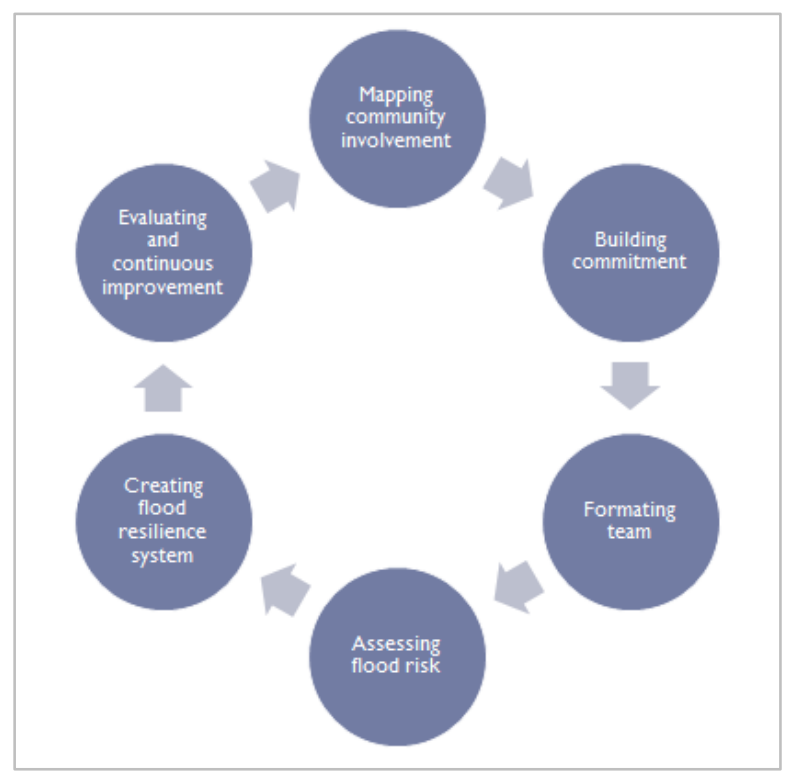

Fig.2. Community-based flood resilience system framework

\section{Conclusions}

The community has the values of local wisdom, namely cooperation and harmony, which have been firmly planted because it is a cultural heritage and educational outcomes of parents. These values further underlie the development of natural resilience and flood risk management systems. The community also has creation, innovation, and high productivity so that it can 
develop fish and vegetable farming by utilizing drainage channels and water leftover from fish farming to fertilize plants. Fish and vegetable yields are used to finance the community flood resilience system. The current flood control program does not only reduce the level of flood risk up to $30 \%$ but also provides operational cost effectiveness resulted from flood risk management system up to $49.2 \%$ in a year.

This is a lesson learned for the government and other parties concerned, that the local community has the readiness to negotiate with the flooding. This can alleviate the burden and responsibility of the government or other parties in dealing with flood problems. Gradually, the government role shifted only as a facilitator.

Further studies are needed, particularly in the wider area or in other areas with different community characteristics, so that a model of the relationship between flood risk management and geographical location and community characteristics can be developed.

Acknowledgments. We would like to thank the people who have assisted in conducting this research, especially the students of the Civil Engineering Department and Doctoral Program of Economic Science, University of Merdeka Malang. This research is financially supported by The Ministry of Research, Technology and Higher Education, the Republic of Indonesia, through a research grant namely Penelitian Terapan (PT) 2020.

\section{References}

[1] P. S. Kaspersen and K. Halsnæs, "Integrated climate change risk assessment: A practical application for urban flooding during extreme precipitation," Clim. Serv., vol. 6, pp. 55-64, 2017.

[2] L. Sedyowati, Turijan, Suhardjono, E. Suhartanto, and M. Sholichin, "Runoff Behavior on Urban Road Intersection based on Flow Profile Simulation," Int. Rev. Spat. Plan. Sustain. Dev., vol. 6, no. 1, pp. 32-44, 2018 .

[3] K. A. Collins, W. F. Hunt, and J. M. Hathaway, "Hydrologic Comparison of Four Types of Permeable Pavement and Standard Asphalt in Eastern North Carolina," J. Hydrol. Eng., vol. 13, no. 12, pp. 1146-1157, 2008.

[4] P. W. B. Nichols, T. Lucke, and C. Dierkes, "Comparing two methods of determining infiltration rates of permeable interlocking concrete pavers," Water (Switzerland), vol. 6, no. 8, pp. 2353-2366, 2014. 
[5] T. Lucke, "Using drainage slots in permeable paving blocks to delay the effects of clogging: Proof of concept study," Water (Switzerland), vol. 6, no. 9, pp. 2660-2670, 2014.

[6] L. Sedyowati, S. Suhardjono, E. Suhartanto, and M. Sholichin, "Runoff velocity behaviour on smooth pavement and paving blocks surfaces measured by a tilted plot," J. Water L. Dev., vol. 33, no. 1, pp. 149-156, 2017.

[7] OECD, Financial Management of Flood Risks, vol. 15, no. 0. Paris: OECD Publishing, 2016.

[8] T. Tingsanchali, "Urban flood disaster management," Procedia Eng., vol. 32, pp. 25-37, 2012.

[9] P. Sayers et al., Flood Risk Management: A Strategic Approach. Paris: UNESCO, 2013.

[10] U. Wehn, M. Rusca, J. Evers, and V. Lanfranchi, "Participation in flood risk management and the potential of citizen observatories: A governance analysis," Environ. Sci. Policy, vol. 48, pp. 225-236, 2015.

[11] A. C. Tyagi and S. Yodmani, Social aspects and Stakeholder Involvement in Integrated flood Management, no. WMO-No. 1008. 2006.

[12] C. Dieperink et al., "Enhancing urban flood resilience as a multi-level governance challenge: An exploration of multi- level coordination mechanisms," pp. 1-26, 2016.

[13] R. J. Dawson, T. Ball, J. Werritty, A. Werritty, J. W. Hall, and N. Roche, "Assessing the effectiveness of non-structural flood management measures in the Thames Estuary under conditions of socio-economic and environmental change," Glob. Environ. Chang., vol. 21, no. 2, pp. 628-646, May 2011.

[14] Associated Programme on Flood Management, "Risk Sharing in Flood Management," 2016.

[15] J. Batica and P. Gourbesville, "Flood Resilience Index-Methodology And Application," 2014.

[16] R. Šakić Trogrlić, G. B. Wright, A. J. Adeloye, M. J. Duncan, and F. Mwale, "Taking stock of community-based flood risk management in Malawi: different stakeholders, different perspectives," Environ. Hazards, vol. 17, no. 2, pp. 107-127, 2018. 
[17] T. L. Gift and J. Marrazzo, “Cost-Effectiveness Analysis,” pp. 482-499, 2007.

[18] N. Haslinda, M. H. Juni, and A. M. Rosliza, "Designing and Conducting Cost-Effectiveness Analysis Studies in Healthcare," Int. J. Public Heal. Clin. Sci., vol. 4, no. 5, pp. 2289-7577, 2017.

[19] J. Ossa-Moreno, K. M. Smith, and A. Mijic, "Economic analysis of wider benefits to facilitate SuDS uptake in London, UK," Sustain. Cities Soc., vol. 28, pp. 411-419, 2017.

[20] R. Wikantiyoso and T. Suhartono, "The Role of CSR in the Revitalization of Urban Open Space for Better Sustainable Urban Development," Int. Rev. Spat. Plan. Sustain. Dev., vol. 6, no. 4, pp. 520, 2018.

[21] J. P. Guilford, Fundamental Statistic in Psychology and Education. New York: McGraw-Hill Book Company, Inc., 1956.

[22] J. Sarwono, Metode penelitian kuantitatif \& kualitatif, Pertama. Yogyakarta : Graha Ilmu, 2006.

[23] L. Sedyowati, G. Chandrarin, G. I. K. Nugraha, and B. Nugroho, "Economic efficiency of community-based flood risk management: An empirical study from Indonesia," J. Water L. Dev., no. No 46, pp. 200 208, 2020.

[24] Cap-Net, GWP, and UNPD, "Integrated water resources management plans - training and operational guide," no. March, pp. 1-98, 2005. 